Available online at http://journal.stkip-andi-matappa.ac.id/index.php/histogram/index

Histogram : Jurnal Pendidikan Matematika 2 (2), 2018, 97-107

\title{
EFEKTIVITAS PENDEKATAN ETNOMATIKA BERBASIS BUDAYA LOKAL DALAM PEMBELAJARAN MATEMATIKA
}

\author{
Vivi Rosida ${ }^{1}$, Muhammad Taqwa ${ }^{2}$, Rahmat Kamaruddin ${ }^{3}$ \\ STKIP Andi Matappa ${ }^{1,2,3}$ \\ * Corresponding Author. Email: vivirosida.child4z@gmail.com \\ Received: 01 September 2018; Revised: 21 September 2018; Accepted: 27 September 2018
}

\section{ABSTRAK}

Penelitian ini bertujuan mengetahui efektivitas pendekatan Etnomatika Berbasis Budaya Lokal dalam pembelajaran Matematika. Instrumen dalam penelitian ini Tes Hasil Belajar, lembar observasi aktivitas siswa dan lembar angket respon siswa untuk melihat bagaimana pendapat siswa mengenai RPP dengan pendekatan Etnomatika berbasis budaya lokal. Hasil penelitian menunjukkan bahwa: (a) Hasil uji coba perangkat pembelajaran diperoleh skor rata-rata dari perolehan siswa pada Tes Hasil Belajar adalah 82,39 dari skor ideal 100, dari 23 siswa, 20 siswa yang mendapat nilai diatas nilai KKM = 75 (b) Aktivitas siswa dalam kelas telah diamati oleh seorang observer, dengan kategori aktivitas siswa yaitu 84,12\%, (c) Respon siswa dengan jumlah siswa 23 memberikan respon positif RPP berada diatas 75\%, yaitu 91,95\%. Semua indikator berada pada kategori "Baik", oleh karena itu, perangkat pembelajaran memenuhi syarat "Efektif".

Kata Kunci: Pendekatan Etnomatika, Budaya Lokal

How to Cite: Rosida, V., Taqwa, M., \& Kamaruddin, R. (2018). Efektivitas Pendekatan Etnomatika Berbasis Budaya Lokal Dalam Pembelajaran Matematika. Histogram: Jurnal Pendidikan Matematika, 2(2), 97-107. doi: http://dx.doi.org/10.31100/histogram.v2i2.235

Permalink/DOI:

http://dx.doi.org/10.31100/histogram.v2i2.235

\section{PENDAHULUAN}

Dalam proses pembelajaran matematika di kelas tidak cukup hanya mengintegrasikan media, tetapi juga diperlukan perangkat pembelajaran yang sesuai. Untuk mengatasi hal tersebut, dipandang perlu untuk mempersiapkan perangkat pembelajaran yang dapat digunakan tidak hanya oleh siswa, tetapi juga oleh guru dalam proses pembelajaran di kelas. Salah satu perangkat tersebut adalah RPP yang dapat dijadikan pedoman dalam melaksanakan pembelajaran di kelas. Ini menunjukkan bahwa dalam kegiatan pembelajaran guru dituntut mempunyai suatu strategi atau pendekatan yang dapat digunakan untuk membangkitkan siswanya aktif dalam pembelajaran. Seseorang akan aktif dalam pembelajaran apabila dia memahami/mengerti apa yang disampaikan oleh 


\section{Histogram: Jurnal Pendidikan Matematika, 2 (2), 2018 - 98 Vivi Rosida, Muhammad Taqwa, Rahmat Kamaruddin}

gurunya, memahami/mengerti artinya siswa tersebut mempunyai makna apa yang dipelajarinya. (Marini Fitriani, 2010)

Istilah etnomatematika berasal dari kata ethnomathematics, yang terbentuk dari kata ethno, mathema, dan tics (Yusuf dkk, 2010) Awalan ethno mengacu pada kelompok kebudayaan yang dapat dikenali, seperti perkumpulan suku di suatu negara dan kelas-kelas profesi di masyarakat, termasuk pula bahasa dan kebiasaan mereka sehari-hari. Kemudian, mathema disini berarti menjelaskan, mengerti, dan mengelola hal-hal nyata secara spesifik dengan menghitung, mengukur, mengklasifikasi, mengurutkan, dan memodelkan suatu pola yang muncul pada suatu lingkungan. Akhiran tics mengandung arti seni dalam teknik. Pada pembelajarannya sendiri kurikulum 2013 menekankan dari pengamatan permasalahan konkret yaitu permasalahan yang benar-benar bisa dibayangkan oleh siswa misalkan menggunakan contoh-contoh dari lingkungan dimana mereka berada yang tentu saja setiap tempat berbeda di Pulau Sulawesi dan Pulau Jawa tentu saja berbeda, maka hendaknya menggunakan kebudayaan yang ada di tempat tersebut sehingga menjadi nyata untuk peserta didik. Isi kurikulum mencakup masalah bagaimana mengurangi berbagai prasangka di dalam tingkah laku radikal dari etnik- etnik tertentu dan di dalam materi apa prasangka-prasangka tersebut dapat dikemukakan. Dalam hal ini, diperlukan studi menyangkut jenis-jenis kebudayaan dari kelompok-kelompok etnis. Demikian pula pendidikan antar kelompok diperlukan sehingga setiap kelompok mengenal kelompok yang lain dan mengapresiasi perbeda- an-perbedaan yang ada. Ide mengintegrasikan etnomatematika ke dalam kurikulum dan pedagogi merefleksikan perkembangan di dalam pendidikan matematika. (Fatimah S. Sirate, 2012),

Dengan mempertimbangkan lingkungan sekitar ataupun budaya lokal anak sehingga terjadi asimilasi antara matematika dan kehidupan mereka. Langkah awal yang perlu dilakukan, dan menjadi fokus dalam penelitian ini adalah melakukan eksplorasiinvestigasi unsur-unsur budaya masyarakat yang memuat konsep-konsep matematika. Hasil eksplorasi tersebut akan dijadikan dasar. Pelestarian kebudayaan daerah dan pengembangan kebudayaan nasional melalui pendidikan baik pendidikan formal maupun nonformal, dengan menggunakan segenap wadah dan kegiatan pendidikan. Pendidikan dan budaya adalah sesuatu yang tidak bisa dipisahkan dalam kehidupan sehari-hari, karena budaya merupakan kesatuan yang utuh dan menyeluruh, berlaku dalam suatu masyarakat dan pendidikan merupakan kebutuhan mendasar bagi setiap individu dalam masyarakat. (Almu Noor Romadoni, 2017) ISSN: 2549-6700 (print), ISSN 2549-6719 (online) 


\section{Histogram: Jurnal Pendidikan Matematika, 2 (2), 2018 - 99 Vivi Rosida, Muhammad Taqwa, Rahmat Kamaruddin}

Pendekatan etnomatematika dimaksudkan untuk membuat materi pelajaran matematika sekolah lebih relevan dan berarti bagi siswa serta untuk menyebarluaskan keseluruhan kualitas pendidikan. Dengan mengimplementasikan pendekatan etnomatematika diharapkan guru dan siswa mendapatkan ide tentang etnomate- matika dan akhirnya dapat meningkatkan prestasi belajar matematika. (Fatimah S. Sirate, 2012), etnomatika diperkenalkan oleh d'ambrosio, seorang matematikawan Brasil yang menyebutkan bahwa etnomatika adalah matematika yang dipraktikkan di antara kelompok budaya dan diedentifikasikan seperti masyarakat nasional suku, kelompok buruh, anakanak dari kelompok usia tertentu dan kelas professional. Hal ini berarti bahwa etnomatika mengacu pada kelompok-kelompok.

Sejalan dengan itu, etnomatika berhubungan langsung dengan budaya lokal. Adapun budaya lokal yang dimaksud adalah: a'bulo sibatang, assamaturu, mappesabbi, sipakatau. A'bulo sibatang pada dasarnya merupakan "filosofi yakni sebatang bambu yang mempunyai banyak ruas yang dimaknai sebagai bentuk kesatuan dan kebersamaan yang kuat. Pohon bambu yang sebelum muncul di permukaan tanah, akarnya telah tersebar didalam tanah dan membuat pondasi yang begitu kuat untuk menopang batang-batang bambu tersebut". Ibaratnya kesatuan kelompok telah terbentuk sedemikian kuat. Setelah tumbuh batang bambu tersusun ruas-ruas yang sama dan memperkokoh batang bambu. Ibarat dari ruas-ruas tersebut adalah suatu kelompok yang bersatu mempertahankan apa yang mereka miliki dengan cara bersama-sama. Samaturu bermakna mendalam melebihi dari makna gotong royong pada masyarakat pada umumnya. Strategi Pembelajaran Samaturu menekankan pada peningkatan kerja sama antarsesama peserta didik serta penguasaan materi yang merata pada setiap peserta didik tersebut. Strategi Samaturu cenderung mengarah pada kerja kelompok dimana semua peserta didik diupayakan untuk bekerja sama menyumbang pikiran diantara sesama mereka dalam memecahkan masalah belajar yang didapatkan selama proses belajar. Mappesabbi berasal dari kata sabbi yang artinya saksi, jadi arti dari mappesabbi ialah mempersaksikan. Dalam kegiatan pembelajaran mappesabbi digunakan pada saat peserta didik mengerjakan tugas, dengan pengerjaan tugas itu harus ada saksi yang betul - betul melihat kinerja ataupun kerja dari seorang peserta didik dalam menyelesaikan semua tugas yang diberikan oleh guru. Sipakatau (Saling Menghargai) adalah konsep yang memandang setiap manusia sebagai manusia. Sipakatau yang bermakna saling menghargai sebagai individu yang bermartabat. 


\section{Histogram: Jurnal Pendidikan Matematika, 2 (2), 2018 - 100 Vivi Rosida, Muhammad Taqwa, Rahmat Kamaruddin}

Berdasarkan latar belakang yang telah diuraikan diatas, maka rumusan masalah penelitian ini adalah: Apakah etnomatika budaya lokal efektif diterapkan dalam pembelajaran matematika?

\section{METODE PENELITIAN}

\section{A. Jenis Penelitian}

Jenis penelitian ini adalah penelitian eksperimen. Dalam penelitian ini melibatkan 1 kelas sebagai kelas eksperimen.

\section{B. Tempat dan Waktu}

Penelitian ini dilaksanakan di SMP Negeri 1 Ma'rang, beralamat di Kec. Ma'rang, Kab.Pangkajene dan Kepulauan.

\section{Populasi dan Sampel}

Populasi penelitian ini adalah seluruh siswa kelas VII di SMP Negeri 1 Ma'rang tahun ajaran 2018/2019. Adapun pemilihan dan penentuan jumlah sampel dengan cara random sampling adalah teknik pengambilan sampel dimana semua individu dalam populasi baik secara sendiri-sendiri atau bersama-sama diberi kesempatan yang sama untuk dipilih sebagai anggota sampel sehingga terpilih kelas VII Al Khawarizmi dengan jumlah siswa 23 orang.

\section{Instrumen Penelitian}

Adapun instrumen dalam penelitian ini adalah tes hasil belajar, lembar observasi aktivitas siswa dan lembar angket respon siswa.

\section{E. Teknik Analisis Data}

\section{Data Tes Hasil Belajar Siswa}

Keberhasilan kelas (ketuntasan klasikal) dapat dilihat dari jumlah peserta didik yang mencapai skor minimal 76 sesuai KKM, sekurang-kurangnya $75 \%$ dari jumlah siswa yang ada dikelas tersebut.

$$
\mathrm{PKB}=\frac{\sum S T}{n s} \times 100 \% \quad(\text { Herry, 2011: 42) }
$$

Keterangan:

PKB : Persentase ketuntasan hasil belajar secara klasikal

ST : Banyaknya siswa yang mencapai ketuntasan hasil belajar

ns : Banyaknya siswa dalam kelas. 
Untuk mengkategorikan tingkat hasil belajar siswa digunakan teknik kategori menurut Abdorrakhman Gintings (2010) sebagai berikut:

Tabel 1. Kriteria Penilaian Hasil Belajar Siswa

\begin{tabular}{cc}
\hline Skor Hasil Belajar & Kategori \\
\hline $80-100$ & Sangat Baik \\
\hline $68-79$ & Baik \\
\hline $55-67$ & Cukup \\
\hline $45-54$ & Kurang \\
\hline$<45$ & Sangat Kurang
\end{tabular}

Sumber: Abdorrakhman Gintings, Tahun : 2010

2. Lembar Pengamatan Aktivitas peserta didik

Penilaian aktivitas siswa dapat dilihat dari persentase siswa yang aktif dalam kegiatan dengan skala penilaian sudjana dalam Rahmat Kamaruddin (2012) sebagai berikut:

1 : jika jumlah siswa yang mengikuti kegiatan sebanyak $25 \%$

2 : jika jumlah siswa yang mengikuti kegiatan sebanyak 25-49\%

3 : jika jumlah siswa yang mengikuti kegiatan sebanyak 50-75\%

4 : jika jumlah siswa yang mengikuti kegiatan sebanyak $75 \%$

3. Keterlaksanaan aktivitas siswa dikatakan efektif jika rata-rata persentase jumlah siswa yang mengikuti kegiatan $>75 \%$.

3. Data Angket Respon Siswa

Analisis data angket respon siswa dihitung dengan menggunakan rumus:

$\mathrm{R}=\frac{F r}{n} \times 100 \% \quad$ (Herry, 2011: 44)

Keterangan:

$\mathrm{R}$ : persentase respon siswa

Fr : frekuensi jawaban tiap aspek

$\mathrm{n}$ : banyak responden 
Histogram: Jurnal Pendidikan Matematika, 2 (2), 2018 - 102

Vivi Rosida, Muhammad Taqwa, Rahmat Kamaruddin

III. HASIL DAN PEMBAHASAN

\section{A. Hasil Analisis Data Tes Hasil Belajar}

Tabel 2. Statistik Skor Hasil Belajar Matematika Siswa Kelas VII Al Khawarizmi SMP Negeri 1 Ma'rang

\begin{tabular}{cc}
\hline Variabel & Nilai Statistik \\
\hline Subjek Penelitian & 23 \\
\hline Skor Ideal & 100,00 \\
\hline Rata-Rata & 83.29 \\
\hline Standar Deviasi & 6.515 \\
\hline Varians & 42.439 \\
\hline Rentang Skor & 19 \\
\hline Skor Minimum & 93 \\
\hline Jumlah Siswa Yang Tuntas & 74 \\
\hline Jumlah Siswa Yang Tidak Tuntas & $\mathbf{2 0}$ \\
\hline
\end{tabular}

(Sumber: Data Primer, Tahun : 2018)

Pada tabel 2 diatas menunjukkan bahwa hasil belajar siswa kelas VII Al Khawarizmi SMP Negeri 1 Ma'rang terhadap pelajaran matematika diperoleh skor ratarata 83.29 dari skor ideal 100 dengan standar deviasi 6.515, varians 42.439. Skor minimum yang diperoleh siswa adalah 74 dan skor maksimum yang diperoleh siswa adalah 93 dengan rentang skor 19.

Tabel 3. Distribusi dan Persentase Skor Hasil Belajar Matematika Siswa Kelas VII Al Khawarizmi SMP Negeri 1 Ma'rang

\begin{tabular}{ccccc}
\hline No & Nilai & Kategori & Frekuensi & Persentase (\%) \\
\hline 1 & $0-54$ & Sangat rendah & 0 & 0 \\
\hline 2 & $55-64$ & Rendah & 0 & 0 \\
\hline 3 & $65-74$ & Sedang & 3 & 13,04 \\
\hline 4 & $75-84$ & Tinggi & 7 & 30,43
\end{tabular}

Copyright (C) 2018, Histogram: Jurnal Pendidikan Matematika ISSN: 2549-6700 (print), ISSN 2549-6719 (online) 


\begin{tabular}{|c|c|c|c|c|}
\hline 5 & $85-100$ & Sangat tinggi & 13 & 55,52 \\
\hline & & & 23 & 100 \\
\hline
\end{tabular}

(Sumber: Data Primer, Tahun : 2018)

Tabel 3 diatas menunjukkan bahwa dari 23 siswa yang mengikuti tes hasil belajar terdapat $0 \%$ siswa yang masuk dalam kategori sangat rendah, $0 \%$ siswa masuk dalam kategori rendah, 13,04\% siswa yang masuk kategori sedang, 30,43\% siswa yang masuk kategori tinggi sedangkan siswa yang masuk kategori sangat tinggi adalah 55,52\%. Hal ini menunjukkan bahwa siswa memperoleh pemahaman yang baik terhadap materi himpunan dengan pendekatan Etnomatika berbasis budaya lokal.

Selain ini tabel diatas juga menunjukkan bahwa banyaknya siswa yang tuntas belajar atau mencapai ketuntasan individu yaitu siswa yang memperoleh skor $75-100$ sebanyak 20 orang dari 23 siswa atau sekitar $82,55 \%$. Jadi banyaknya siswa yang belum tuntas yaitu siswa yang memperoleh skor 0 - 75, sebanyak 3 orang atau sekitar 13,04\% .

\section{B. Hasil Analisis Data Aktivitas Siswa}

Tabel 4. Rata-rata Presentase Ketuntasan Aktivitas Siswa

\begin{tabular}{ccccc}
\hline Pertemuan & $\begin{array}{c}\text { Jumlah Nilai } \\
\text { yang } \\
\text { diperoleh }\end{array}$ & $\begin{array}{c}\text { Total } \\
\text { Maksimum }\end{array}$ & $\begin{array}{c}\text { Persentase } \\
(\%)\end{array}$ & $\begin{array}{c}\text { Persentase } \\
\text { Aktivitas } \\
\text { Siswa }\end{array}$ \\
\hline I & 66 & 84 & $100 \%$ & $78,57 \%$ \\
\hline II & 73 & 84 & $100 \%$ & $86,90 \%$ \\
\hline III & 73 & 84 & $100 \%$ & $86,90 \%$ \\
\hline \multicolumn{5}{c}{ Rata-rata (\%) } \\
\hline
\end{tabular}

(Sumber: Data Primer, Tahun : 2018)

Tabel 4 diatas juga menunjukkan bahwa persentase aktivitas siswa yang mengikuti kegiatan yaitu pada pertemuan pertama jumlah siswa yang mengikuti pembelajaran sebanyak $78,57 \%$, pertemuan kedua $86,90 \%$ dan pertemuan ketiga $86,90 \%$. Jadi rata-rata jumlah siswa yang mengikuti kegiatan selama proses pembelajaran dengan menggunakan perangkat pembelajaran dengan pendekatan Etnomatika berbasis budaya lokal 84,12\%. 


\section{Histogram: Jurnal Pendidikan Matematika, 2 (2), 2018 - 104 Vivi Rosida, Muhammad Taqwa, Rahmat Kamaruddin}

\section{Hasil Analisis Data Respon Siswa}

Respon siswa terhadap perangkat pembelajaran matematika berdasarkan angket yang diberikan ke siswa sebagai berikut:

Tabel 5. Respon Siswa Terhadap Pembelajaran Matematika dengan Pendekatan Etnomatika Berbasis Budaya Lokal

\begin{tabular}{|c|c|c|c|c|c|c|}
\hline \multirow[b]{2}{*}{ Aspek Respon Siswa } & \multicolumn{3}{|c|}{ Respon negatif } & \multicolumn{3}{|c|}{ Respon positif } \\
\hline & $\begin{array}{l}\text { Tidak } \\
\text { Setuju }\end{array}$ & $\begin{array}{c}\text { Kurang } \\
\text { Setuju }\end{array}$ & $\begin{array}{c}\text { Persentase } \\
(\%)\end{array}$ & Setuju & $\begin{array}{l}\text { Sangat } \\
\text { Setuju }\end{array}$ & $\begin{array}{c}\text { Persentase } \\
(\%)\end{array}$ \\
\hline \multicolumn{7}{|c|}{$\begin{array}{l}\text { Pembelajaran matematika menggunakan model pembelajaran pendekatan etnomatika } \\
\text { berbasis budaya local }\end{array}$} \\
\hline $\begin{array}{l}\text { (Mappesabi/mempersaksikan } \\
\text { ) melatih saya berpikir dalam } \\
\text { menyelesaikan soal } \\
\text { matematika materi himpunan }\end{array}$ & - & 1 & $4,34 \%$ & 15 & 7 & $95,65 \%$ \\
\hline $\begin{array}{l}\text { (A'bolu } \\
\text { sibatang/kebersamaan)dapat } \\
\text { meningkatkan semangat saya } \\
\text { dalam belajar matematika }\end{array}$ & 1 & 2 & $13,04 \%$ & 9 & 11 & $86,95 \%$ \\
\hline $\begin{array}{l}\text { (Mappesabbi /mempersaksi) } \\
\text { membuat saya lebih akitf } \\
\text { dalam proses pembelajaran }\end{array}$ & - & 4 & $17,39 \%$ & 12 & 7 & $82,60 \%$ \\
\hline $\begin{array}{lrr}\text { Belajar } & \text { matematika } & \text { dengan } \\
\text { pendekatan } & \text { etnomatika } \\
\text { berbasis } & \text { budaya } & \text { lokal } \\
\text { membuat } & \text { materi } & \text { mudah } \\
\text { diingat } & & \\
\end{array}$ & - & 1 & $4,34 \%$ & 11 & 11 & $95,65 \%$ \\
\hline $\begin{array}{l}\text { (Mappesabbi/mempersaksi) } \\
\text { membantu meningkatkan } \\
\text { motivasi saya untuk belajar } \\
\text { matematika materi himpunan }\end{array}$ & - & 3 & $13,04 \%$ & 11 & 9 & $86,95 \%$ \\
\hline $\begin{array}{l}\text { (assamaturuseng/mufakat) } \\
\text { sangat bermanfaat dalam } \\
\text { proses pembelajaran } \\
\text { matematika }\end{array}$ & - & 4 & $17,39 \%$ & 2 & 17 & $82,60 \%$ \\
\hline $\begin{array}{l}\text { (A'bolu } \\
\text { sibatang/kebersamaan) }\end{array}$ & - & 1 & $4,34 \%$ & 12 & 10 & $95,65 \%$ \\
\hline
\end{tabular}


membuat saya lebih tertarik dalam belajar matematika

(Mappisabbi/Mempesaksi) dapat meningkatkan rasa percaya diri saya dalam belajar matematika

$0 \% \quad 8 \quad 15 \quad 100 \%$

(A'bulo

sibatang/kebersamaan) saya dapat berbagi pengetahuan dengan teman pada saat $\begin{array}{llllll}2 & 1 & 13,04 \% & 10 & 10 & 86,95 \%\end{array}$ pembelajaran berlangsung

(Mappisabbi/Mempersaksi) membuat saya rajin mengerjakan soal-soal latihan

Rata-rata (\%) $\mathbf{0 , 3} \quad 1,8 \quad 91,26 \%$ 10 $\mathbf{1 0 , 9} \quad \mathbf{9 0 , 8 6 \%}$

(Sumber: Data Primer, Tahun : 2018)

\begin{tabular}{|c|c|c|c|c|c|c|}
\hline \multirow{2}{*}{$\begin{array}{l}\text { Aspek Respon } \\
\text { Siswa }\end{array}$} & \multicolumn{3}{|c|}{ Respon negatif } & \multicolumn{3}{|c|}{ Respon positif } \\
\hline & $\begin{array}{l}\text { Tidak } \\
\text { Setuju }\end{array}$ & Kurang & $\begin{array}{c}\text { Persentase } \\
(\%)\end{array}$ & Setuju & $\begin{array}{l}\text { Sangat } \\
\text { Setuju }\end{array}$ & $\begin{array}{c}\text { Persentase } \\
(\%)\end{array}$ \\
\hline 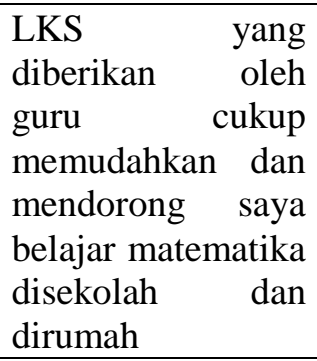 & - & - & $0 \%$ & 7 & 16 & $100 \%$ \\
\hline $\begin{array}{lr}\text { LKS } & \text { yang } \\
\text { siberikan } & \\
\text { mendorong } & \text { saya } \\
\text { belajar matematika } \\
\text { lebih baik }\end{array}$ & - & 2 & $8,69 \%$ & 9 & 12 & $91,30 \%$ \\
\hline $\begin{array}{lr}\text { Bahasa } & \text { yang } \\
\text { digunakan } & \text { pada } \\
\text { LKS } & \text { cukup } \\
\text { dimudah dipahami }\end{array}$ & 1 & 3 & $17,39 \%$ & 3 & 16 & $82,60 \%$ \\
\hline
\end{tabular}

(Sumber: Data Primer, Tahun : 2018)

Berdasarkan tabel 5 diatas respon siswa terhadap perangkat pembelajaran dengan pendekatan Etnomatika berbasis budaya lokal berjumlah 23 orang dengan respon siswa ISSN: 2549-6700 (print), ISSN 2549-6719 (online) 


\section{Histogram: Jurnal Pendidikan Matematika, 2 (2), 2018 - 106 Vivi Rosida, Muhammad Taqwa, Rahmat Kamaruddin}

yang tidak setuju $1,30 \%$, siswa yang kurang setuju $7,82 \%$, siswa yang setuju $43,47 \%$, dan siswa yang setuju 47,39\% dengan demikian respon positif perangkat pembelajaran yaitu 90,86\% sehingga perangkat pembelajaran ini dikatakan memenuhi syarat keefektifan. Sedangkan respon siswa terhadap Lembar Kerja Siswa yang tidak setuju 0,87\%, siswa yang kurang setuju 6,08\%, siswa yang setuju 33,9\%, siswa yang sangat setuju 59,13\%, dengan demikian respon postif terhadap Lembar Kerja Siswa yaitu 93,04\% sehingga Lembar Kerja Siswa memenuhi syarat keefektifan.

\section{KESIMPULAN DAN SARAN}

\section{A. Kesimpulan}

Berdasarkan teori yang dikemukakan bahwa syarat keefektifan jika 3 indikator berada pada kategori "baik". Indikator tersebut adalah hasil belajar, respon siswa dan aktivitas siswa. Pembahasan hasil penelitian terhadap pembelajaran dengan pendekataan Etnomatika berbasis budaya lokal pada pembelajaran matematika kelas VII Al Khawarizmi SMP Negeri 1 Ma'rang, telah memenuhi syarat kriteria "efektif".

\section{B. Saran}

Berdasarkan penelitian yang telah dilaksanakan ada beberapa saran yang dapat dipertimbangkan dalam pembelajaran matematika untuk meningkatkan perhatian siswa yaitu 1) Penelitian serupa dengan pendekatan Etnomatika berbasis budaya lokal yang telah dihasilkan masih perlu diujicobakan pada sekolah lain, 2) Para guru matematika sebaiknya memperhatikan budaya lokal disetiap daerah dan menghubungkannya dengan matematika. 


\section{DAFTAR PUSTAKA}

Gintings, A. (2010). Esensi Praktis belajar dan Pembelajaran, Humaniora, Bandung.

Romadoni, A, N. (2017). Aspek-aspek Etnomatika Pada Budaya Masyarakat Banjar Dan Penggunaan Aspek-Aspek Tersebut Untuk Pengembangan Paket Pembelajaran Matematika. Tesis. Yogyakarta: Universitas Sanata Dharma.

Cahyono, A, D, \& Daryanto. (2014). Pengembangan Perangkat Pembelajaran. Yogyakarta: Gava Media.

Herry. (2011). Pengertian Matematika Sekolah. Jakarta: P4TK.

Kamaruddin , R. (2012). Pengembangan Bahan Ajar Materi Geometri Berdasarkan Teori Belajar Van Hiele Berbasis Karakter untuk Siswa Kelas VII SMP. Tesis. Tidak Dipublikasikan. Makassar. PPs UNM Makassar.

Marini, F. (2010). Pengembangan Perangkat Pembelajaran Matematika dengan Pendekatan Kuantum di Kelas VIII SMP, Jurnal Pendidikan Matematika vol.4 no.1: 2.

Sirate, F. (2012). Implementasi Etnomatematika Dalam Pembelajaran Matematika Pada Jenjang Pendidikan Sekolah Dasar. Jurnal Lentera Pendidikan. Vol. 15 No.1: 43.

Yusuf, M, W. (2010). Ethnomathematics (a Mathematical Game in Hausa Culture). International Journal of Mathematical Science Education Technomathematics Research foundation. http://www.tmrfindia.org/sutra/v3i16.pdf. 